\title{
PRESENCIA DE NOTHOFAGUS ALPINA (POEPP. ET ENDL.) OERST. (FAGACEAE) EN EL BORDE COSTERO DE LA REGION DEL MAULE, CHILE CENTRAL
}

\author{
NOTHOFAGUS ALPINA (POEPP. ET ENDL.) OERST. (FAGACEAE) IN THE \\ COASTAL AREA OF THE MAULE REGION, CENTRAL CHILE
}

This note reports the finding of a small population of Nothofagus alpina (Poepp. et Endl.) Oerst. (Fagaceae) in the valley of Cayurranquil river $\left(35^{\circ} 58^{\prime} \mathrm{S}, 72^{\circ} 39^{\prime} \mathrm{W}\right.$ ) extending the known distribution of this species into the coast ranges of the Maule region, Chile.

\author{
César A. Sepúlveda ${ }^{1} \&$ Alexandra Stoll2,3 \\ ${ }^{1}$ Comité Nacional Pro-Defensa de la Fauna y Flora (CODEFF), 2 Sur 606, Talca, Chile. \\ ${ }^{2}$ Institute of Botany, Dresden University of Technology, 01069 Dresden, Germany. \\ ${ }^{3}$ Correspondencia a alexandrastoll@ hotmail.com
}

Nothofagus alpina (Poepp. et Endl.) Oerst. (Fagaceae) "raulí" es una especie arbórea de interés forestal que se halla en los bosques caducifolios subantárticos de Chile y Argentina (Rodríguez et al. 1983, Villagrán et al.1998, Rodriguez \& Quezada 2003). Su distribución actual en Chile se da en ambas cordilleras del país. Particularmente en la Cordillera de la Costa de Chile central se encuentra espacialmente en forma discontinua e inserta en una matriz forestal. En el registro florístico realizado por San Martín \& Doll (1999) en el borde costero de Chile central se señala que el límite septentrional de $N$. alpina ocurre en los $36^{\circ} 03^{\prime} \mathrm{S}$ y $72^{\circ} 28^{\prime} \mathrm{W}$. La población habita en un predio forestal denominado "El Mirador 3" cerca del límite norte de la Región del Bío-Bío.

Esta nota reporta el hallazgo de Nothofagus alpina en la cuenca del Río Cayurranquil, situado a unos $12 \mathrm{~km}$ al norte del límite documentado por San Martín \& Doll (1999), en el extremo suroeste de la Región del Maule. La ubicación exacta se da en los $35^{\circ} 58^{\prime} \mathrm{S}$ y $72^{\circ} 39^{\prime} \mathrm{W}$, a una altitud de $475 \mathrm{~m}$ snm (Fig. 1). La población se encuentra en un sector que presenta un grado mediano de intervención antrópica, dado principalmente por la histórica sustitución del bosque nativo por cultivos agrícolas y forestales. La población de $N$. alpina se incorpora en la formación fragmentaria de Nothofagusobliqua y $N$. glauca situada en la ladera occidental de la cuenca. Aquí N. alpina crece en la depresión de afluente de la quebrada principal. El sitio es relativamente húmedo, explicando así el acompañamiento por especies tales como Aextoxicon punctatum, Persea lingue, Gevuina avellana y Jovellana punctata. La población de $N$. alpina se compone de seis individuos adultos (8 $25 \mathrm{~cm}$ diámetro), acompañados por unos cuatro árboles juveniles en el estrato arbustivo.

En la cercanía directa (= $500 \mathrm{~m}$ alrededor) de la población descrita no se han localizado otros individuos de $N$. alpina. Fuera de este radio sigue una zona de intervención humana con matorrales y plantaciones de Pinus radiata.

Material de estudio: Chile, Séptima Región, provincia de Cauquenes, Ramadillas-Cayurranquil, 475 msnm, 35 $58^{\prime}$ S y $72^{\circ} 39^{\prime}$ W, II-2003, César Sepúlveda y Alexandra Stoll s/n. Herbario de la Universidad de Talca $\mathrm{N}^{\circ} 2700$. 


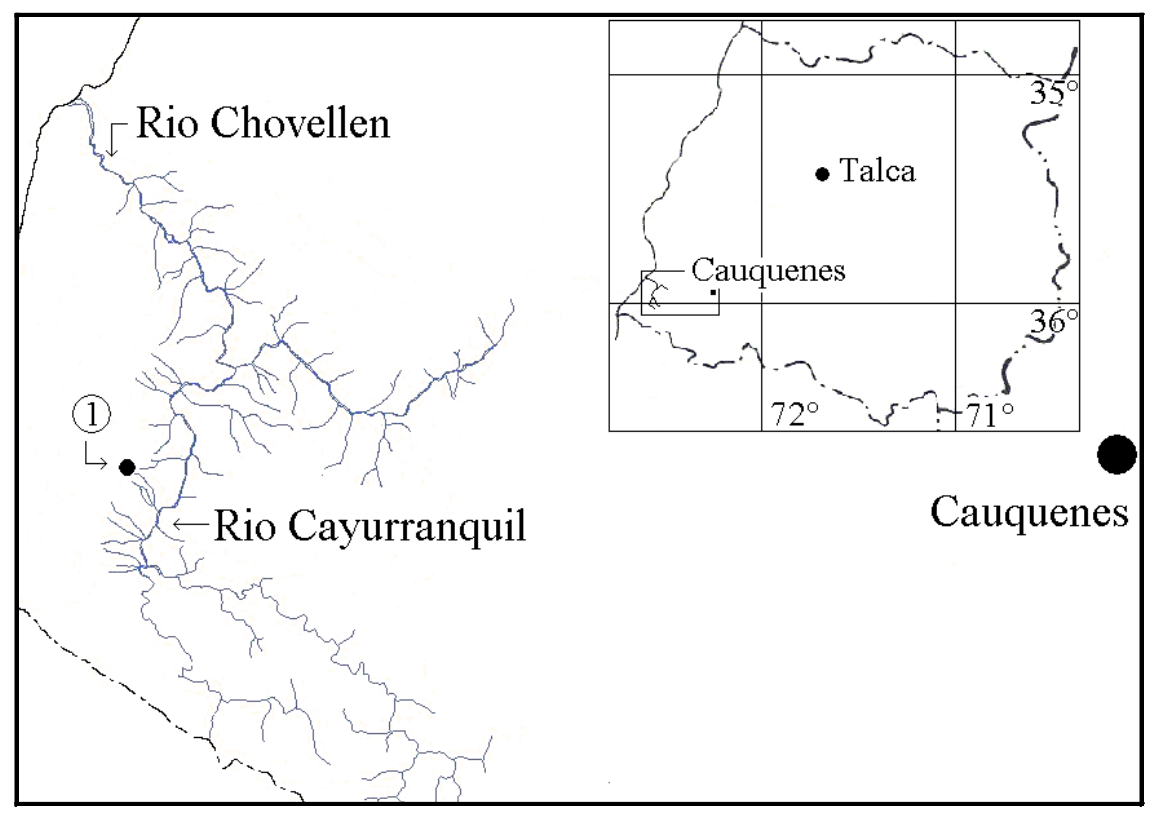

Figura 1: Ubicación de la quebrada del río Cayurranquil, el punto (1) indicando el lugar del hallazgo de Nothofagus alpina.

\section{AGRADECIMIENTOS}

Se agradece el apoyo de J. San Martín y P. Peñailillo, del Instituto Biología y Biotecnología Vegetal de la Universidad de Talca. A CODEFF Región del Maule por el préstamo de materiales. Especial agradecimiento a Emeline Muffat-es-Jacques, Roberto L. Inzulza y a los habitantes del sector.

\section{BIBLIOGRAFIA}

Rodríguez, R., O. Matthei, \& M. Quezada. 1983. Flo- ra arbórea de Chile. Ed. Universidad de Concepción. Concepción. Chile 408 pp.

Rodríguez, R. \& M. Quezada. 2003. Fagaceae. Flora de Chile Vol. 2 (2):64-76.

SAn Martín, J. \& U. Doll. 1999. Nueva localidad geográfica para "raulí", Nothofagus alpina (Poepp. et Endl.) Oerst., Fagaceae, en la Cordillera de la Costa de Chile central. Gayana Botanica 56: 66-68.

Villagrán, C., Le-Quesne, C., Aravena, J.C., Jiménez, H. \& F. Hinojosa. 1998. El rol de los cambios de clima del cuaternario en la distribución actual de la vegetación de Chile central-sur. Gamberger Geographische Schriften 15: 227242. 